\title{
TRAVESSIAS FORMATIVAS NA DOCÊNCIA UNIVERSITÁRIA: APRENDIZAGENS EXPERIENCIAIS DO/NO PROFACE
}

\author{
FORMATIVE TRAJECTORIES IN UNIVERSITY TEACHING: \\ EXPERIENTIAL LEARNING FROM / IN PROFACE
}

Fabrício Oliveira da Silva* Ana Carla Ramalho Evangelista Lima** Amali de Angelis Mussi**

\section{RESUMO:}

Este trabalho analisa experiências formativas de docentes universitários a partir das contribuições de uma ação extensionisța do Programa de Formação Acadêmica e Contextualização de Experiências Educacionais - ProFACE. Trata-se de uma experiência que tem por objetivo compreender como o referido Programa possibilita o desenvolvimento de saberes constituídos pela experiência cotidiana de exercer a docência universitária. Reflete modos de desenvolvimento da docência e elucida visões que professores de diferentes areas do conhecimento possuem em torno da pratica educativa na universidade. Este é um estudo qualitativo, que se centra nos sentidos que os docentes atribuem ao processo formativo vivenciado na universidade, em que a extensão se curriculariza pela formação docente, sobretudo considerando as práticas educativas e o que se concebe delas na docência universitária. Entre alguns resultados, evidenciou-se que a avaliação, a leitura e escrita e as práticas pedagógicas figuraram como objeto de análise para a criação de novos modos de compreender e fazer a docência na universidade.

Palavras-chave: Docência universitária; Formação extensionista; Práticas educativas.

\begin{abstract}
:
This work analyzes formative experiences of university teachers based on the contributions of an extensionist action of the Academic Training Program and Contextualization of Educational Experiences - ProFACE. It is an extensionist experience that aims to understand how the said Program enables the development of knowledge constituted by the daily experience of teaching at university. It reflects on modes of development of teaching and presents views shared by teachers of different areas of knowledge around the educational practice at university. This is a qualitative study that focuses on the meanings that teachers attribute to the formative process experienced in the university where extension is made part of the curriculum through teacher training, especially considering the educational practices and what is conceived of them in university teaching. Among some results, evaluation, reading and writing and pedagogical practices were evidenced as objects of analysis for the creation of new ways of understanding and teaching at university.
\end{abstract}

Keywords: University Teaching; Extensionist Training; Educational Practices. 


\section{Introdução}

A extensão universitária tem se configurado, também, enquanto espaço formativo que busca mobilizar docentes a se envolverem em ações que os deslocam a pensarem sobre a sua atuação profissional na universidade. Neste viés, alguns programas de formação universitária se configuram como ações extensionistas que são desenvolvidas com os professores universitários com vistas a criar espaço de formação e reflexão sobre o trabalho docente. Ações formativas e extensionistas em serviço tem se constituído uma necessidade cada vez mais emergente no contexto da docência universitária, dada a existência de professores, geralmente nos cursos da modalidade bacharelado, que não possuem o curso de licenciatura. Parece ser paradoxal, mas a profissão de professor pode ser exercida por profissionais que não têm a formação específica para o exercício da docência. Essa situação tem implicado em debates a respeito dos saberes, práticas e formação de professores no cenário educacional, promovendo reflexões e propostas que visam compreender a necessidade do desenvolvimento profissional docente atrelado aos processos formativos pelos quais devem vivenciar os sujeitos que estão na atuação profissional, sobretudo sem a formação específica para este fim.

Considerando toda essa problemática, e percebendo como a formação é transversal nesse processo, este trabalho se originou das experiências formativas desenvolvidas no âmbito do Programa de formação acadêmica e contextualização de experiências educacionais - ProFACE, que se constitui em um plano de formação que integra o Projeto Pedagógico Institucional - PPI da Universidade Estadual de Feira de Santana - UEFS. Trata-se de um Programa de formação em serviço, voltado para docentes da instituição. O referido Programa integra a política de formação da Pró-reitoria de graduação da universidade, com o objetivo de promover ações que buscam investir nos professores e gestores institucionais, propiciando espaços para ampliar as possibilidades de sua formação pedagógica e para o desenvolvimento profissional docente.

O referido Programa origina-se das ações desenvolvidas pelo Núcleo de Estudos e Pesquisas em Pedagogia Universitária - NEPPU. Trata-se de um grupo de pesquisa vinculado ao Departamento de Educação da universidade e que tem tradição em realizar pesquisas cuja temática central se desenvolve em torno da pedagogia universitária, a partir de suas várias entradas. Neste contexto, o NEPPU dedica-se a discutir a docência universitária, ofertando aos docentes da instituição momentos formativos por meio de seminários, cursos de extensão, desenvolvimento de pesquisas de natureza colaborativa, além de Programas como o ProFACE.

O ProFACE nasceu como uma política de formação docente que tem suas preocupações voltadas para a promoção de condições efetivas de possibilitar desenvolvimento de saberes, produzidos nas reflexões sobre os processos de ensino-aprendizagem que emergem do cotidiano das práticas dos professores da UEFS. Neste sentido, o Programa propõe momentos intensivos de formação para os professores nos períodos de recesso acadêmico e em momentos permanentes ao longo do semestre. É direcionado por um conjunto de princípios norteadores e referenciais, objetivos e estrutura, que apontam necessidades formativas específicas do ser professor universitário.

Nesta lógica, os docentes são convidados a realizar cursos, oficinas e a participar de encontros formativos, a partir dos quais a docência universitária é objeto de discussão e estudo. Tal ação tem possibilitando criação de espaços formativos, sobretudo para docentes que são bacharéis e que não possuem curso de licenciatura. Na UEFS, essa é uma realidade bastante presente, principalmente porque os 14 dos 28 cursos de graduação da universidade são de bacharelados e contam, em razão disso, com um grande quantitativo de professores que não possuem a licenciatura e revelam dificuldades nos processos de ensino na universidade. Essa realidade tem sido uma preocupação da instituição, que através de ações e Programas, como o ProFACE, cria condições formativas para que professores de diversas áreas possam discutir planejamento de aulas, processos avaliativos, desenvolvimento de estratégias e metodologias de ensino, entre outros.

A partir desse cenário, o presente trabalho se propõe a analisar relatos de docentes participantes do Programa, trazendo à baila as concepções sobre docência universitária e sua tessitura no cotidiano da prática pedagógica que realizam. Busca, neste aspecto, evidenciar modos e formas de compreensão sobre os fazeres e saberes docentes e como o Programa oportuniza a criação de experiências pedagógicas a partir dos diálogos que os professores realizam nos encontros realizados pelas ações do mesmo.

O estudo envolveu docentes de diferentes áreas do conhecimento, que participaram de rodas de conversa em diferentes sessões de formação do ProFACE, visando entender: Como os docentes lidam com a docência no cotidiano da universidade? Qual o papel da reflexão para orientar e reorientar as práticas educativas? E, por fim, como os professores concebem o papel da formação para suas práticas educativas na universidade?

\section{Percurso metodológico}

$\mathrm{O}$ estudo se inscreve na abordagem qualitativa, por ser uma metodologia que se caracteriza pela compreensão dos fenômenos, que geralmente são as ações dos indivíduos, grupos ou organizações em seu ambiente ou contexto social, como é o caso do estudo em tela, que se arrola a partir das compreensões que quatro professores desenvolvem em torno de suas inserções no Programa ProFACE e consequente participações em rodas de conversa com demais docentes do Ensino Superior. Nesta abordagem, o pesquisador tem por prática analisar os dados, interpretando-os segundo a perspectiva dos próprios sujeitos que participam da pesquisa, sem se preocupar com representatividade numérica, generalizações estatísticas e relações lineares de causa e efeito.

Neste sentido, o presente estudo prima por compreender os significados construídos pelos docentes em torno das ações formativas desenvolvidas pelo ProFACE, razão que nos levou a adotar a perspectiva dos estudos biográficos (NÓVOA; FINGER, 2014), 
exatamente por ser esse um método de base qualitativa, que propõe analisar as histórias de formação, centrando a investigação nos sentidos (FERRAROTTI, 1988) que o próprio sujeito imprime para a produção de experiências durante o percurso formativo. Logo, a nossa opção por esta abordagem de pesquisa efetivouse, dentre outras razões, por possibilitar uma perspectiva de se estudarem as trajetórias de formação de professores universitários no ProFACE, focalizando as subjetividades do processo de formação e de produção de experiências na docência universitária.

Os dispositivos utilizados foram rodas de conversa e registro de ações formativas realizadas por quatro participantes. As rodas envolveram vários docentes de diferentes cursos e áreas de formação, sendo desenvolvidas por um grupo de professores que possuem só o bacharelado, mas também com docentes com formação em licenciatura. Em cada roda de conversa, elegeu-se um participante que ficou responsável por fazer os registros sobre o que se discutiu nas rodas. Nessa dinâmica, os registros são as reflexões que o grupo produziu, mas congrega modos de compreensões de quem fez o registro.

Para este trabalho, analisamos os registros e, por meio deles, buscamos evidenciar como as práticas educativas se constituem nas redes dialógicas que o ProFACE possibilita. As rodas de conversa foram gravadas e analisadas a partir dos registros que cada docente, um em cada roda de conversa, produziu. Assim, foram quatro distintas rodas, ocorridas em momentos simultâneos das ações formativas do ProFACE. Em cada uma discutiu-se uma temática específica que envolve diretamente as ações dos docentes nos contextos das práticas organizativas que eles desenvolvem na universidade.

Deste modo, em uma roda os professores discutiram questões sobre avaliação da aprendizagem, revelando tessituras e modos de desenvolvimento dos processos avaliativos. Nesta roda, debateram-se questões epistemológicas sobre o papel da avaliação na universidade a partir de concepções em torno da aferição, verificação e avaliação da aprendizagem centrada nas ações do professor com vistas à promoção da aprendizagem dos estudantes. Em outra roda, as discussões focalizaram as práticas docentes na universidade, por meio da qual se buscou problematizar as práticas, compreendendo-as em suas dimensões pedagógicas, inerentes ao trabalho dos professores em sala de aula, mas também das práticas educativas que apontam para ações mais amplas do trabalho docente na universidade. Com vistas a centrar as discussões num problema que é geral na universidade, uma outra roda de desenvolveu a partir das reflexões sobre o trabalho de leitura e escrita com os estudantes, possibilitando conhecer modos de ações, intervenções, práticas e saberes dos docentes no que tange às dinâmicas do trabalho realizado na universidade em torno da leitura e escrita de textos.

Com essa metodologia, buscou-se realizar reflexões sobre como as práticas educativas se constituíram no tocante aos modos de se analisar como se estruturam as ações pedagógicas na universidade, bem como revelar os anseios $\mathrm{e}$ as necessidades formativas no que tange à docência, em se considerando o fato de alguns docentes não possuírem formação em licenciatura. Assim, os dispositivos puderam contribuir para o entendimento das questões de práticas educativas e sua relação com o processo de ensino-aprendizagem que os docentes vivenciam em seu cotidiano, balizadas pela argumentação e reflexões que cada um produziu ao considerar seus saberes, competências, mas sobretudo por evidenciarem a necessidade de um processo formativo constante, que dê condições à apreensão e ao desenvolvimento de estratégias metodológicas que possibilitem o desenvolvimento do ensino com maior condição de produzir aprendizagens nos estudantes.

Nesta seara, os professores em formação no ProFACE implicam-se num movimento de reflexão da prática a partir dos efeitos que a mesma provoca a quem ela mais interessa, nesses casos aos sujeitos que as realiza e que, portanto, se colocam em uma atitude de formação.

\section{Segundo Alarcão (2005),}

Os professores desempenham um importante papel na produção e estruturação do conhecimento pedagógico porque refletem, de uma forma situada, na e sobre a interação que se gera entre o conhecimento científico [...] e a sua aquisição pelo aluno, refletem na e sobre a interação entre a pessoa do professor e a pessoa do aluno, entre a instituição escola e a sociedade em geral. Desta forma, têm um papel ativo na educação e não um papel meramente técnico que se reduza à execução de normas e receitas ou à aplicação de teorias exteriores à sua própria comunidade profissional (ALARCÃO, 2005, p. 176)

Alarcão (2005), em suas pesquisas, conceitua o professor reflexivo, descrevendo-o como um profissional que necessita saber quem é e as razões pelas quais atua, conscientizando-se do lugar que ocupa na sociedade. Portanto, a consciência de si e de seu papel na universidade deve compor sempre uma forma de o professor provocar-se a partir do que o outro reflete sobre ele e sobre sua prática. A autora acrescenta ainda que "os professores têm de ser agentes ativos do seu próprio desenvolvimento e do funcionamento das escolas como organização ao serviço do grande projeto social que é a formação dos educandos" (ALARCÃO, 2005, p. 177). No contexto das propostas de reflexão, a universidade é essa escola que precisa cuidar da formação dos seus educandos. Nessa lógica, os docentes universitários são os educandos que, num processo de formação continuada, corroboram com o seu próprio desenvolvimento profissional ao movimentá-lo na consciência de seus saberes e fazeres, por meio da reflexão de sua prática e dos sentidos que a ela se atribuem.

Por esta perspectiva metodológica, em que os professores se colocam colaborativamente num percurso formativo para estabelecer diálogos que fecundem seus saberes e práticas, criam-se modos de promoção da formação em serviço que significam uma forma de produção de saberes sobre a docência, que impacta diretamente na elevação da qualidade do trabalho docente na universidade. As ações reflexivas e dialógicas representam uma forma de informar, formar, refletir, conhecer e atualizar a dinâmica do trabalho docente, de modo colaborativo e produtivo. A instituição universitária, segundo Zabalza (2004), considera que formar, melhorar como profissional e aprender a ensinar são questões que dependem de cada professor, sobretudo quando, no exercício da docência, eles se permitem aprender com as práticas do outro, instaurando uma formação necessária e vital no contexto das práticas 
organizativas e colaborativas que os docentes desenvolvem em seu fazer na universidade.

\section{A formação experiencial na docência universitária: reflexões sobre a prática pedagógica}

A formação profissional em ações extensionistas tem sido valorizada e realizada nas universidades como um modo de possibilitar o desenvolvimento das aprendizagens experienciais que ganham notoriedade nas reflexões que os professores fazem de sua prática pedagógica. Essa perspectiva reflexiva sobre a formação docente tem sido discutida por alguns pesquisadores, como é o caso de Cunha (2009), quando considera a necessidade de formação específica para que o professor possa desenvolver seu trabalho, levando em consideração a complexidade que a docência requer para além de um saber específico. $\mathrm{Na}$ docência universitária, pela não necessidade do curso de licenciatura para o desenvolvimento das atividades docentes, é comum termos "um perfil acadêmico de professor universitário baseado na especificidade do conhecimento que alicerça a sua profissão" (CUNHA, 2009, p.94). No entanto, a docência é um elemento complexo que compreende múltiplas ações, as quais dizem respeito ao processo de ensino-aprendizagem, que constitui bases pedagógicodidáticas necessárias ao seu exercício.

Neste sentido, o exercício profissional requer do professor saberes específicos, não somente de uma determinada área ou especificidade do conhecimento, mas de saberes e conhecimentos relativos às competências para lidar com o processo de ensinoaprendizagem, que demandam ações, atitudes e relações que se logram por percursos formativos e também pelo desenvolvimento experiencial da profissão docente. É, portanto, no cotidiano da universidade e das práticas organizativas do trabalho docente, além da formação, que os professores se inserem numa dinâmica organizacional de aprendizagem constante sobre sua atuação profissional.

São saberes requeridos aos docentes universitários que, segundo Zabalza (2004), se fundamentam em três funções basilares, quais sejam: o ensino, a pesquisa e a administração em diversos setores da instituição. É, sobretudo, para o ensino que a problemática se evidencia, pois no que tange a esse aspecto há múltiplas atividades complexas em torno da docência, com vistas ao desenvolvimento de processos de ensino-aprendizagem, que os professores precisam conhecer e saber desenvolver. No sentido formal, docência é o trabalho dos professores, que vai muito além da ação rotineira de ministrar aulas. As práticas organizativas e funcionais da docência, tais como ter um bom conhecimento sobre a disciplina, saber como explicá-la, como desenvolver estratégias de ensino que possibilitem o desenvolvimento de aprendizagens, tornam-se, na contemporaneidade, atividades mais complexas, e com o surgimento de novas tecnologias, e, consequentemente, novas condições de trabalho, requerem dos professores ainda maior investimento formativo.

Ao analisarmos as competências inerentes aos professores, constantes na Lei 9394/96, especificamente no seu art. 13, encontramos as seguintes incumbências para esses profissionais: a) Participar da elaboração do projeto pedagógico; b) Elaborar e cumprir o plano de trabalho; c) Zelar pela aprendizagem dos alunos; d) Estabelecer estratégias de recuperação para alunos de menor rendimento; f) Ministrar os dias letivos e horas-aula estabelecidos; g) Participar integralmente dos períodos dedicados ao planejamento, à avaliação e ao desenvolvimento profissional. Assim, independente de qual seja o nível de atuação dos professores, essas competências não são tão simples e requerem preparação para que elas, em seu conjunto, sejam efetivamente cumpridas.

No que tange à docência universitária, segundo Cunha (2006), essas incumbências são ainda mais complexas, pois envolvem outros processos que demandam competências específicas do ensino, mas também competências específicas de aprendizagens relativas às diferentes áreas de formação do estudante. Assim, formar advogados, enfermeiros, médicos, engenheiros e até mesmo professores envolve outros saberes e práticas que tornam a docência ainda mais complexa para aqueles que com ela lidam na universidade. Parta além dessa problemática, ainda é necessário pensar numa docência que seja de qualidade e que gere bons resultados formativos.

De acordo os estudos de Vasconcellos e Oliveira (2011, p. 4), "a qualidade, da docência é um fator importante que, com frequência, tem sido ignorado pela universidade". É pensando na qualidade da docência na universidade que se logra, também, a partir de um processo formativo, que o ProFACE tem possibilitado encontros entre os docentes com vistas a trabalhar a aprendizagem experiencial que emerge das reflexões que cada professor desenvolve em sua dinâmica formativa pela participação no Programa.

A roda de conversa com o foco nas práticas docentes na universidade contou com a participação de 22 docentes de diversas áreas que discutiram problemas evidenciados nas metodologias de ensino dos professores. Segundo o registro da docente relatora da roda, as principais questões sobre as práticas emergem da falta de criatividade dos professores em realizar inovações, pois ficam presos em comportamentos reprodutivos no que diz respeito às estratégias e metodologias de ensino. Neste sentido, Isabel ${ }^{1}$ relata que

\begin{abstract}
As reflexões evidenciaram que os professores tendem, no dia a dia, a reproduzir práticas e procedimentos rotineiros e burocráticos, o que termina por empobrecer o processo de ensino e aprendizagem. Nesse sentido, enfatizam-se as dificuldades do ensino na área de saúde, propondo que sejam desenvolvidas estratégias em sala de aula, a fim de que o aluno possa intervir mais ativamente. (Isabel, registro escrito, 2016)
\end{abstract}

Ao considerar o reconhecimento de professores do campo da Saúde, que não possuem licenciatura, sobre as práticas repetitivas, a docente percebe que as dificuldades são evidenciadas pelos colegas e postas na reflexão dialógica entre os pares. Esse comportamento sugere que é na roda de conversa que as experiências do cotidiano emergem como pistas para que um docente com maior experiência e conhecimento sobre estratégias de ensino dialogue com os colegas e lhes possibilite conhecer e desenvolver, a partir disso, novas estratégias. Neste aspecto, a reflexão sobre a docência, como modo de concebê-la em suas limitações face às ações repetitivas de metodologias, 
evidencia um movimento reflexivo e consequentemente sugestivo de melhoria da prática docente, levando-a, como concebe Vasconcellos e Oliveira (2011), a uma promoção de qualidade educativa que passa a ser pensada pelo viés da formação em serviço no ProFACE e que, consequentemente, possibilita a elevação da qualidade de ensino, compreendida no uso de diferentes metodologias, adensada em didática e postura coerente com a docência universitária.

Se a formação tem como finalidade a elevação do nível de qualidade do ensino e a potencialização do desenvolvimento da aprendizagem do estudante, também para o docente deve elevar a atividade de reflexão sobre práticas. Esses momentos são considerados por Nóvoa (2007) como importantes para a evolução na carreira. Contudo, são poucos os que se envolvem com a devida atenção nesta atividade, tendo em vista que os momentos de encontro entre os docentes oportunizados pelas instituições têm caráter mais administrativo do que pedagógico. Na contramão dessa lógica, o ProFACE se insurge numa dinâmica formativa pautada na reflexão das ações pedagógicas dos docentes, numa perspectiva dialógica que converge para a construção de saberes oriundos das questões cotidianas do trabalho dos professores na universidade. De certo modo, essa formação em serviço ganha sentido, pois ela é tecida da realidade educativa aos movimentos que se fazem necessários para mudanças e desenvolvimentos de práticas que possibilitem ao docente desenvolver-se profissionalmente, construindo saberes inerentes às demandas de ensino que desenvolve na universidade.

Deste contexto, os relatos que a professora Isabel produz permite-nos compreender o lugar da inovação metodológica, que se constitui por uma diversidade de estratégias com vistas a atender às necessidades que os estudantes revelam aos seus professores na tessitura de suas práticas pedagógicas na universidade. A ideia de uma formação permanente surge como princípio fundante do reconhecimento da centralidade discursiva e dialógica que se processam em encontros com os pares. Isso tem a ver com o processo de formação continuada que se principia no ProFACE como uma formação que se constitui na aprendizagem experiencial de cada docente, que leva em consideração o cotidiano do trabalho educativo.

A docência universitária é concebida como uma profissão em que professores formam outros sujeitos, razão pela qual, nessa profissão, os processos constituem a relevância das práticas educativas e não o produto em si, ou seja, a formação pela formação. Formar outros como função primeira da docência universitária implica numa constante ação reflexiva sobre os processos que se desenvolvem balizados pela responsabilidade com o que se produz na formação para o outro. Assim, a profissão de professor, "que tem como resultado uma obra e não um produto, implica a responsabilidade humana e social e é, por isso, uma profissão de natureza muito especial". (GEORGEN, 2006, p. 90). O desafio que se evidencia mais ainda na contemporaneidade incide justamente em pensar a formação de docentes que formam outros sujeitos a partir das realidades que cada um vive, que precisam ser partilhadas para a promoção dos processos colaborativos na universidade.

Essa lógica evidencia que a docência universitária se constitui experiencialmente nos processos formativos que mobilizam o professor a estar em constante movimento reflexivo, em busca de entendimento dos diferentes modos de tornar-se professor na universidade. E, diante desta situacionalidade, é importante destacar a necessidade de os docentes estarem em busca constante de novas formas de aprendizagem, questionando-se sempre, como o faz Bolzan (2008, p. 109), quando problematiza as seguintes questões: "Como aprender a docência ou como construir-se como docente neste nível de ensino? Quais as implicações dos processos formativos para a educação superior e sua relação com a professoralidade?"

Segundo Bolzan (2008), a pedagogia universitária deve ser compreendida como um espaço em movimento, no qual a própria docência universitária em ação pode ser revisitada. Isso implica no reconhecimento de que a formação se pereniza nas ações reflexivas que cada um desenvolve, a partir da busca de compreensão em torno de sua própria prática. Dessa forma, a universidade precisa ser concebida como um espaço de formação, na busca da concretização de uma docência de qualidade no ensino superior.

Em outra da roda de conversa, o professor Pedro relata que:

Durante a roda de conversa, foi salientada a
necessidade de os docentes diversificarem as
estratégias de ensino, de modo a dinamizar o processo
de ensino e aprendizagem em sala de aula. Ao final, os
participantes propuseram que sejam promovidos outros
momentos formativos, mediante a troca de
experiências, socialização de metodologias de ensino
inovadoras, práticas pedagógicas, entre outras, que
contribuam para a melhoria da prática docente. (Pedro,
registro escrito, 2016)

A ideia de melhoria da prática pedagógica advém da percepção dos encontros com docentes que estão vivenciando o cotidiano das aprendizagens experienciais. Isso sugere que é preciso trabalhar uma docência universitária que reflita os desafios impostos pela comunidade acadêmica, sobretudo por colocar o estudante como o centro do processo, para quem seja possível desenvolver diferentes estratégias a partir das quais trabalhe-se, entre outras, com "a exposição docente, ou com um vídeo, ou com um texto de livro, ou ainda com um estudo de caso, ou mesmo com uma experiência que o aluno traz" (ANASTASIOU, 2009, p.48).

$\mathrm{O}$ processo de ensino e aprendizagem potencializa-se pelo diálogo entre os pares e promove condições para melhoria das práticas, pois é por meio das reflexões coletivas em sala que os interesses serão despertados e as aprendizagens edificadas. Nas rodas, passa-se a refletir com os pares sobre o que os professores precisam fazer com os estudantes para lograrem êxito nas aprendizagens que se esperam destes. Assim, o confronto entre ideias, compreensões, erros, equívocos, tudo isso deve ser considerado tanto na atividade docente, como no percurso formativo, como forma de potencializar novos modos de fazer a docência, inovando e gerando outras estratégias. Pela formação do ProFACE, o professor, nas rodas, perde a centralidade de ser o conhecedor e abre-se a novas aprendizagens experienciais com os colegas. 


\section{Preocupações com o processo avaliativo e as competências da leitura e escrita na universidade}

A avaliação da aprendizagem é uma preocupação central nas práticas docentes na universidade, sobretudo quando a esta se entrecruzam as questões inerentes ao desempenho de leitura e escrita de estudantes. São preocupações distintas, mas que aqui, para um efeito didático da organização do nosso texto, trataremos de modo interrelacional, mesmo porque as rodas de conversa que tomam como centralidade as discussões sobre as práticas avaliativas na universidade mantêm estreita relação com os processos de leitura e escrita dos estudantes. Em outras palavras, a leitura e escrita são objetos constantes de avaliação dos professores, estando presentes quando a discussão gira em torno dos processos avaliativos na universidade. Em qualquer área do conhecimento, a leitura e escrita é basilar e se insurge como um fundamento das metas que cada docente precisa cumprir, tendo em vista potencializar as competências comunicativas dos estudantes.

Ao analisarmos os registros produzidos a partir da roda que discutiu leitura e escrita na universidade, percebemos que os docentes principiam sua discussão focando a compreensão que têm para a leitura e para a escrita. Neste sentido, evocam dois autores consagrados do campo das Letras para partirem das reflexões que os fazem conceber esses dois processos como fundamentais e essenciais nas travessias formativas dos estudantes na universidade. Assim, nos registros da roda de conversa, encontramos citações produzidas pela professora Raquel, as quais transcrevemos aqui para que possamos compreender as concepções que a referida relatora da roda adota para sistematizar o que ela concebe no tocante aos processos de leitura e escrita na universidade. Neste sentido, o seu relato é iniciado e justificado com as citações que faz de Petit (2009) e Lispector (1991), que demarcam a centralidade das discussões que se produziram na roda em torno dessa temática, concebendo a leitura e a escrita como fundamentos essenciais da aprendizagem dos estudantes na universidade. Assim, a professora abre o registro que fez da roda:

\begin{abstract}
"A leitura contribui assim para criar um pouco de "jogo" no tabuleiro social, para que os jovens se tornem um pouco mais atores de suas vidas, um pouco mais donos de seus destinos e não somente objetos do discurso dos outros." (PETIT, 2009, p.100)²

"Quero escrever esquálido e estrutural como o resultado de esquadros, compassos e agudos ângulos de estreito enigmático triângulo. "Escrever" existe por si mesmo? [...] Escrever é uma indagação. É assim? Será que estou me traindo? Será que estou desviando o curso de um rio? Tenho que ter confiança nesse rio abundante. Ou será que ponho uma barreira no curso de um rio? Tento abrir as comportas, quero ver a água jorrar com ímpeto." (LISPECTOR, 1991, p. 14) ${ }^{3}$
\end{abstract}

Tanto no que tange à leitura e escrita, as citações reforçam a ideia de que a docente defende os princípios de autonomia reflexiva que esses dois processos devem gerar nos estudantes. Assim, na docência universitária, a preocupação com a leitura e escrita emerge como princípio necessário à promoção de autoria e autonomia reflexiva. No entanto, as reflexões que os professores fazem em torno das práticas avaliativas sobre leitura e escrita revelam uma preocupação com o baixo desempenho dos estudantes, mas ao mesmo tempo se evidenciam proposições de atendimento e acolhimento destes sujeitos em suas necessidades formativas, concernentes ao desenvolvimento da leitura e da escrita na universidade.

Considerando o que foi debatido nessa roda,
Raquel sinaliza que a leitura e escrita tem problemas, o que ela chama de entraves e dificuldades, que de algum modo tem estreita relação com os processos avaliativos que se fazem do estudante na universidade. A respeito das dificuldades sobre leitura e escrita dos estudantes, a professora assim sintetiza sua compreensão do que os colegas discutiram na roda:

Ao dialogar sobre o modo como o tema da roda de conversa leitura e produção de texto na universidade aparece no cotidiano docente, evidenciam-se os principais entraves/dificuldades que os professores enfrentam, quais sejam: Ausência de autoria no texto oral e escrito: os alunos costumam mais reproduzir os discursos dos autores do que construir sentidos perante as leituras realizadas; Presença de citações na produção escrita sem apropriação real das ideias e sem estabelecimento de diálogo com os autores lidos; Falta de autonomia e autoria das ideias; Dificuldade com relação às questões formais/de registro da língua (grafia de palavras); Pouca leitura e/ou leitura sem atribuição/produção de sentidos; Ausência da prática da reescrita (os alunos não compreendem a importância dessa etapa como constituinte da escrita acadêmica e revelam, portanto, sofrimento e angústia quando são solicitados a fazê-la); Dificuldades de compreensão leitora e produção escrita constatadas de maneira recorrente pelos pares em reuniões; Passividade, silenciamento nas aulas com diversos significados, entre eles o não entendimento do conteúdo pelo aluno. (Raquel, registro escrito, 2016).

$\mathrm{O}$ relato permite-nos inferir que, durante a roda de conversa, logo, durante o percurso formativo dos professores no ProFACE, a questão da leitura e escrita é depreendida entre tessituras avaliativas que os docentes fazem, ao analisarem as práticas que desenvolvem com os estudantes, em que a leitura e escrita são processos em desenvolvimento. A identificação das dificuldades e dos entraves em torno do tema aponta para uma necessidade de reorientação de práticas de ensino e, consequentemente, avaliativas, que coloca o professor no desafio de mudar seu modo fazer a docência, com vistas à promoção das aprendizagens dos estudantes no campo da leitura e escrita. Assim, muito além de discutir e de identificar os problemas e entraves em torno da questão, os professores se movem a descolar o problema, focalizando-o em um novo contexto que figura como desafio da própria docência universitária. Neste movimento, o relato de Raquel faz-nos perceber a viabilidade discursiva de transformação das práticas e aprendizagens de outras que permitam o professor lograr êxito no ensino e na avaliação da leitura e escrita dos estudantes.

$O$ ponto de vista analítico que Raquel desenvolve emerge da ótica de observar as dificuldades dos estudantes a partir do que consensuam os docentes participantes da roda, quando abordam tais entraves e dificuldades a partir das avaliações que se processam. Assim, dizer que os estudantes não exercem autoria, pouco reescrevem ou ainda revelam pouca capacidade interpretativa se insurge como elementos de análise de dados que se originam do cotidiano da docência efetivada na universidade. São das vivências e experiências com os estudantes que os professores revelam as tessituras das dificuldades que aqueles têm com a leitura e escrita, enquanto que estes mostram, no percurso formativo, a necessidade de instaurar novas práticas educativas que demandem aprendizagens, tanto para uns, como para outros.

Sobre isso, Fontana e Guedes-Pinto (2009) esclarecem:

Esse percurso que temos seguido tem nos mostrado como o aprendizado desse saber-fazer do cotidiano escolar demanda uma inserção, um mergulho nas 
relações sociais de cada realidade vivida. $\mathrm{E}$ esse mergulho precisa de um tempo, pois a aprendizagem constitui-se na vivência do processo. (FONTANA E GUEDES-PINTO 2009, p. 18 e 19)

Aprendizagens sobre como auxiliar os estudantes, desenvolvendo estratégias de ensino que potencializem o uso da leitura e escrita na universidade, constitui-se em uma ação de saber-fazer que se processa no contexto do cotidiano da docência universitária, assim como para Fontana e Guedes-Pinto (2009), saberes como estes se logram nas aprendizagens da vivência no processo cotidiano que se desenvolve com os estudantes no ambiente escolar.

Segundo Cunha (2006), a docência se efetiva nas artimanhas do local em que a desenvolvemos. Assim, perceber as dificuldades de leitura e escrita dos estudantes dá sentido a isso para a reorganização das práticas educativas e aponta para uma necessidade de se produzir a docência universitária em sintonia com o cotidiano em que ela acontece, razão, também, da emergência de uma formação que se ancore pela realidade local em que a docência é desenvolvida. É disso queCunha (2006) falou quando defendeu a ideia de que "é improvável poder abordar a temática da docência separada do lugar em que se produz enquanto profissão" (CUNHA, 2006, p. 56).

De certo modo, isso tem a ver com as práticas educativas que o processo formativo do ProFACE revela, ao possibilitar que os docentes de diferentes áreas do conhecimento dialoguem, reflitam sobre seu fazer e construam novos mecanismos, sobretudo no campo da avaliação da aprendizagem, que demandem desenvolvimento de práticas organizativas do trabalho docente na universidade, que se fundamentem em princípios epistemológicos de saberes para a docência.

No que se refere especificamente à avaliação e as concepções que os docentes produzem em torno dela, evidencia-se uma preocupação quanto à natureza do processo avaliativo, principalmente em se considerando a tessitura da avaliação. Deste modo, o elemento qualitativo e sua relação com o quantitativo evidencia modos de conceber a funcionalidade do processo avaliativo na prática dos docentes, o que está revelado nos registros que Tereza faz da roda de conversa, cujo foco foi a avaliação. Assim, a professora nos diz que

\begin{abstract}
A ideia de que a docência possui uma dimensão própria e que a avaliação é parte dela foi lembrada como um aspecto importante e, em certo sentido, problemático para os cursos não diretamente envolvidos na formação de professores, em que é mais difícil fazer uma reflexão sobre essas dimensões, o que favorece a reprodutibilidade dos procedimentos canônicos Derivada dessa discussão, levantou-se o problema da avaliação ser quantitativa ou qualitativa, ou mesmo quali-quanta. Essa discussão derivou de uma questão levantada sobre a qualidade das avaliações. Elementos como o significado das notas, o rendimento médio dos alunos, a adequação dos instrumentos de avaliação, etc junto às necessidades de se reorientar práticas avaliativas foram contemplados em algumas falas. (Tereza, Registro escrito, 2016)
\end{abstract}

A avaliação é concebida como parte da docência, situando-se em um lugar de relevância no campo do saber necessário que os professores precisam construir para ensinar. Nessa lógica argumentativa, a avaliação, ao tempo que se apresenta como uma dimensão importante da atividade docente, revela uma problemática que emerge da situação de professores que avaliam, mas que não tiveram uma formação específica para saber avaliar. Neste sentido, a avaliação é um problema na prática docente para alguns professores, que veem na formação uma possibilidade para desenvolverem aprendizagens a respeito dos processos inerentes à avaliação.

A qualidade das avaliações e a preocupação com as notas são elementos de problematização do processo avaliativo, que aparece no registro como um entrave que os docentes enfrentam no momento em que precisam desenvolver estratégias e dinâmicas de avaliação na perspectiva qualitativa e esbarram na lógica quantitativa de converter isso em nota, para atender ao sistema da universidade. De certo modo, a avaliação é percebida como uma ação que movimenta a reorganização das práticas, e, por isso, mantém estreita relação com os processos de ensino na docência universitária. Avaliar não é uma ação tão simples e requer saberes específicos. A avaliação se consagra como uma epistemologia educativa que vai além da mera lógica de produzir e aplicar um instrumento avaliativo para saber se os estudantes aprenderam ou não aquilo que o professor ensinou.

Luckesi (2002), um dos estudiosos que tem se debruçado em torno da temática, considera que a avaliação é um dos aspectos mais problemáticos do processo de ensino, porque normalmente utilizada apenas com o sentido de verificação, não apresenta efeitos na dinâmica da ação pedagógica conduzida pelo docente. $\mathrm{O}$ autor faz suas ponderações, alertando para o real significado da avaliação:

\begin{abstract}
A avaliação atravessa o ato de planejar e de executar: por isso contribui em todo o percurso da ação planificada. [...] A avaliação se faz presente não só na identificação da perspectiva político-social, como também na seleção dos meios alternativos e na execução do projeto, tendo em vista a sua construção. [...] E uma ferramenta necessária ao ser humano de construção dos resultados que planificou produzir [...] Ela faz parte de seu modo (do professor) de agir, e por isso, é necessário que seja usada da melhor forma possível. (LUCKESI, 2002, p.118).
\end{abstract}

Segundo Luckesi (2002), bem como segundo o relato da professora Tereza, a avaliação tem uma situação problemática para os professores, uma vez que é um tema complexo que envolve ações como planejar, executar, avaliar, reavaliar, autoavaliar etc. Neste sentido, tem-se um tema para o qual os saberes são necessários e construídos tanto nas vivências com as práticas avaliativas, como também nos percursos formativos nos quais se envolvem os professores. Avaliar vai além do processo de aferição ou de verificação dos problemas, tais quais evidenciados pela professora Raquel, quando analisa e reflete sobre os problemas de leitura e escrita dos estudantes.A percepção de que eles evidenciam dificuldades com a linguagem pode ter raízes num processo, apenas, de verificação. Os problemas com a leitura e escrita, neste contexto, só deixarão de existir se, de fato, a avaliação passar a integrar a prática docente, fazendo sentido a partir da ações que se insurgem em processos mais amplos, desde o desenvolvimento de estratégias de ensino, passando pelas práticas avaliativas, gerando novas táticas metodológicas de reconduzir a aprendizagem para que os estudantes superem suas dificuldades.

De igual modo, o professor, no contexto de sua docência, vivencia dificuldades com o processo de ensino, revelando, assim como os estudantes no que tange 
à leitura e escrita, dificuldades pela ausência de formação específica para este fim. É nesta teia argumentativa que o ProFACE vai consolidando uma discussão entre os pares que possibilita aos participantes lograrem modos de compreensão sobre suas realidades educacionais no que se refere ao ensino, criando condições reflexivas de identificação dos problemas que assolam sua prática educativa, com vistas a promover a criação de novas estratégias e modos de ensinar na universidade.

\section{Considerações finais}

O estudo evidencia que a atividade docente como prática social complexa envolve conhecimentos, habilidades, atitudes, expectativas e visões de mundo implicadas pelas diferentes estratégias pedagógicas que utilizam os professores. Desse modo, a formação dialógica possibilitada pelo ProFACE se constituiu num processo de diferenciação e convergências, relações formais e informais que se produziram pela reflexões e aprendizagens experienciais, que facultaram a troca de saberes pelos docentes, logradas no cotidiano de sua prática educativa na universidade.

Pela experiência extensionista e formativa constituída nos diálogos entre docentes participantes do Programa, é possível afirmar que o cotidiano das práticas educativas se emancipam como lócus da reflexão que cada docente faz para poder compartilhar com seus pares novas metodologias e estratégias de ensino, que se fabricam não fora do contexto da instituição, mas levando-se em consideração os saberes e fazeres de cada um, que se alteram, complementam e se inovam a partir dos diálogos que se estabelecem nas rodas de conversa do ProFACE.

O estudo permitiu concluir que a ausência de formação específica para ensinar tem sido um problema para docentes universitários. No entanto, esse fato não tem impedido que docentes aprendam a partir das vivências cotidianas no que tange ao ensino que desenvolvem na universidade. Assim, parte dos professores universitários não possui uma formação especifica para o ensinar, mas, a despeito disso, ensinam e são bem-sucedidos em muitos momentos, sobretudo porque se abrem ao diálogo com os colegas e participam de ações formativas, como a proposta pelo ProFACE. Esses resultados são evidenciados em decorrência de saberes oriundos da experiência, aliados a saberes disciplinares.

Os registros permitem concluir, ainda, que os professores universitários têm uma preocupação com suas práticas educativas, bem como com os processos de avaliação que reorientam as práticas. Evidenciam percepções sobre os sentidos e efeitos do trabalho com leitura e escrita, mostrando como os estudantes revelam dificuldades nesse campo. Pelos relatos, vê-se que a preocupação com a situação vai além de ser um problema só do estudante, pois volta-se enquanto preocupação dos professores para poder problematizar e reorientar as práticas. Abre-se, neste contexto, a possibilidade de formação extensionista por pares, valorizando e reconhecendo as ações do ProFACE, que se singularizam na medida em que mobilizam os professores a refletirem sobre sua prática e, além disso, a produzirem novas.

\section{Notas:}

${ }^{1}$ Em atendimento ao que preconiza o Comitê de Ética de Pesquisa com seres humanos, os nomes dos colaboradores são fictícios para que se preserve as identidades dos mesmos.

2 PETIT, Michèle. Os jovens e a leitura: uma nova perspectiva. $2^{\mathrm{a}}$ ed. Tradução de Celina Olga de Souza. São Paulo: Ed. 34, 2009.

3 LISPECTOR, Clarice. Um sopro de vida. Rio de Janeiro: Francisco Alves Editora, 1991.

\section{Referências}

ALARCÃO, Isabel (Coord.). Formação reflexiva de professores: estratégias de supervisão. Porto: Porto Editora, 2005.

ANASTASIOU, Léa das Graças Camargos. A teoria e a prática de processos de formação continuada do docente universitário. In: ALMEIDA, Maria Isabel de; PIMENTA, Selma Garrido (Orgs.). Pedagogia universitária. São Paulo: EDUSP, 2009. p. 39-70.

BOLZAN, D. P. V. Pedagogia universitária e processos formativos: a construção do conhecimento pedagógico compartilhado. In: Trajetórias e processos de ensinar e aprender: lugares, memórias e culturas [recurso eletrônico] ENDIPE, 14., 2008. Porto Alegre: EDIPUCRS, 2008. p.102-120.

CUNHA, Maria Isabel da. Verbetes: formação inicial e formação continuada. Enciclopédia de pedagogia universitária. Brasília: MEC/INEP, 2006, p. 354.

CUNHA, M.I. Trajetórias e lugares da formação do docente da educação superior: do compromisso individual à responsabilidade institucional. Revista Brasileira de Formação de Professores, v.1, n.1, p.110-128, mai./2009.

FERRAROTTI, Franco. Sobre a autonomia do método biográfico. In: NÓVOA, NÓVOA, António; FINGER, Mathias (Orgs.). O método (auto) biográfico e a formação. Natal: EDUFRN; São Paulo: Paulos, 2014

FONTANA, Roseli C.; GUEDES-PINTO, Ana Lúcia. Trabalho escolar e produção do conhecimento. In: SHIGUNOV NETO, Alexandre; MACIEL, Lizete Shizue Bomura (Org.). Desatando os nós da formação docente. 2. ed. Porto Alegre: Mediação, 2009.

GEORGEN, P. Universidade e compromisso social. In: RISTOFF, D.; SAVEGNANI, P. Universidade e compromisso social. Brasília, DF: Instituto Nacional de Estudos e Pesquisas Educacionais Anísio Teixeira, 2006. p. 65-95.

\section{LUCKESI, C.C. Avaliação da aprendizagem escolar:} estudos e proposições. 14. ed. São Paulo: Cortez, 2002.

\section{NÓVOA, António. O regresso dos professores.}

Comunicações. Presidência Portuguesa do Conselho da União Européia. Conferência Desenvolvimento profissional de professores para a qualidade e para a equidade da aprendizagem ao longo da vida. Lisboa, 2007.

VASCONCELLOS, M. M. M.; OLIVEIRA, C. C. Docência na universidade: compromisso profissional e qualidade de ensino na graduação. Educação, Santa Maria, v. 36, n.2, p. 219-234, mai./ago. 2011.

ZABALZA, M.A. O ensino universitário: seu cenário e seus protagonistas. Porto Alegre: Artmed, 2004. 